\title{
Empreendedorismo corporativo como novas oportunidades de negócio
}

DOI: 10.47224/revista master.v6i11.107

\author{
Danilo Faria de Moura \\ Emanuel Soares Ponciano \\ Aline Andrade Fresneda \\ Arnaldo Fernandes Junior \\ Gabriel Severino da Silva Filho \\ Gabriela Monteiro Lavagnolli \\ Jéssica Marques Dias
}

e-mail: danilofmoura@yahoo.com.br

\section{Resumo}

O papel do empreendedor vai muito além de constituir e gerir financeiramente uma empresa. São necessários conhecimento e estratégias eficientes para manter o empreendimento em constante evolução. Diante disso, o presente artigo objetiva identificar quais os maiores obstáculos do gestor nesse processo, bem como maneiras de superar as dificuldades inerentes à gestão. Para o levantamento de informações teóricas utilizou-se de metodologia de pesquisa bibliográfica. A metodologia empregada para o desenvolvimento deste estudo inclui a observação da realidade, pontoschave, teorização, hipóteses de solução e aplicação à realidade (Arco de Maguerez). Por meio do presente estudo, buscou-se encontrar ações eficientes para conduzir a empresa e gerir seus colaboradores de modo a garantir que o empreendimento se mantenha em ascensão. Conclui-se que se faz necessário o desenvolvimento de um plano de carreira atraente, a criação de um plano de participação final nos lucros pelos colaboradores, oferecer um treinamento eficiente e incentivar o empreendedorismo corporativo para a solução dos problemas identificados.

Palavras-chave: Empreendedorismo; Home Office; Empreendedorismo Corporativo.

\begin{abstract}
The role of the entrepreneur goes far beyond setting up and managing a company financially. Knowledge and efficient strategies are needed to keep the enterprise in constant evolution. In view of this, this article aims to identify the greatest obstacles of the manager in this process, as well as ways to overcome the difficulties inherent to management. For the collection of theoretical information bibliographic research methodology was used. The methodology used for the development of this study includes the observation of reality, key points, theorization, solution hypothesis and application to reality (Arco de Maguerez). Through this study, we sought to find efficient actions to conduct the company and manage its employees in order to ensure that the enterprise remains on the rise. It is concluded that the development of an attractive career plan, the creation of a final profit-sharing plan by the employees, offer efficient training and encourage corporate entrepreneurship to solve the identified problems is necessary.
\end{abstract}

Keywords: $\quad$ Entrepreneurship; Home Office; Corporate Entrepreneurship.

1

\section{INTRODUÇÃO}

Para Dornelas (2020, p. 9) “empreendedorismo tem a ver com realizar ou colocar em prática algo que o empreendedor tem pensado, sempre com o objetivo de gerar valor para a sociedade." Em outra citação, o autor retrata que:
O empreendedor possui características extras, além dos atributos do administrador, e alguns atributos pessoais que somados a características sociológicas e ambientais permitem a realização de inovações dentro da corporação, identificação de oportunidades e a diferenciação. É interessante observar que 
o empreendedor de sucesso leva consigo ainda uma característica singular, que é o fato de conhecer como poucos a área de atuação da empresa, o que leva tempo e requer experiência. (DORNELAS, 2008, p.19)

O presente artigo é resultante de atividades realizadas no Curso de Administração. Sua elaboração se deu por meio da Metodologia da Problematização com o Arco de Maguerez e foi vivenciada tendo como marco norteador a seguinte temática: uma nova era pautada em informação, Home Office e profissionais multiníveis. Para o levantamento de informações teóricas utilizou-se de metodologia de pesquisa bibliográfica.

Dornelas (2020, p. 9) ressalta que "funcionários de grandes e médias empresas são cada vez mais solicitados a contribuir com ideias para fazer a empresa crescer, alguns vão além, colocam as ideias em prática, trazendo resultados às suas empregadoras." Para o autor eles são os empreendedores corporativos, responsáveis por inovar em empresas estabelecidas.

Chiavenato (2012, p. 8) contribui nesse contexto afirmando que "o empreendedor é também o grande detetive das oportunidades, tendo que ser ágil para aproveitar as oportunidades ocasionais, antes que outras pessoas o realizem."

Este artigo tem como ponto de partida a observação da realidade em uma empresa do segmento alimentício da cidade de Araguari. Partindo dos pontos observados levantou-se as problemáticas e realizou-se pesquisas bibliográficas para embasamento de hipóteses de soluções, sendo uma delas explorada pelos autores como proposta de intervenção e melhoria dos pontos relacionados.

Cury apresenta uma versão mais romântica do empreendedorismo ao citar que:

Ser um empreendedor é executar os sonhos, mesmo que haja riscos. É enfrentar os problemas, mesmo não tendo forças. É caminhar por lugares desconhecidos, mesmo sem bússola. É tomar atitudes que ninguém tomou. É ter consciência de que quem vence sem obstáculos triunfa sem glória. É não esperar uma herança, mas construir uma história... Quantos projetos você deixou para trás? Quantas vezes seus temores bloquearam seus sonhos? Ser um empreendedor não é esperar a felicidade acontecer, mas conquistá-la. (CURY, 2003, p. 30)

Fazendo a transposição da visão de Cury para o empreendedorismo corporativo levantou-se os questionamentos: Quantas ideias não são colocadas em prática, engavetadas pelo comodismo ou por autoridades maiores? Quantas carreiras são findadas sem que os objetivos pessoais sejam atingidos?

O empreendedorismo corporativo se faz cada vez mais necessário, principalmente nesse estágio vivenciado pela humanidade em que a informação não é mais uma exclusividade, estando disponível a todos em abundância a um clique. Nesse novo cenário o empreendedor tem desafio de agregar valor às novas informações, transformando-as em conhecimento aplicado em seus negócios, ou nas empresas em que trabalham.

Dornelas (2003, p. 37) ressalta que "as diferenças entre os domínios empreendedor e administrativo podem ser comparadas em cinco dimensões distintas de negócio: orientação estratégica, análise das oportunidades, comprometimento dos recursos, controle dos recursos e estrutura gerencial."

Para se destacar frente a uma concorrência cada vez mais ampla, as empresas devem investir em inovações que garantam um melhor relacionamento com seus clientes, atendendo os pressupostos e necessidades por eles indicados. Justifica-se esse artigo em virtude da relevância para as empresas em ter uma cultura de desenvolvimento de competências empreendedoras para que possam ter perenidade de suas operações, e consequentemente contribuir com a economia local.

\section{IDENTIFICAÇÃO DA PROBLEMÁTICA}

Para Chiavenato (2012, p. 181) “a gestão participativa é um processo compartilhado entre o empreendedor e sua equipe de trabalho." O autor ainda afirma que a administração participativa, baseada nas pessoas, tem sido apontada como a alavanca para o progresso, pois ela representa o envolvimento das pessoas na gestão do negócio, além de uma evolução do processo democrático. 
É mister ressaltar que as empresas oferecem produtos cada vez mais similares e o atendimento ao cliente e agilidade na entrega ganham destaque na avaliação final do consumidor. Fatores como qualidade e adequação às normas estabelecidas por órgãos reguladores somam na visão que os clientes possuem sobre os produtos, pois os julgam essenciais, além de serem vistoriados constantemente por agências reguladoras.

Tendo em vista a observação da realidade destacouse os pontos cruciais para as falhas apontadas na empresa pesquisada:

- Garantia de Estabilidade;

- Ausência de treinamentos;

- Desmotivação;

- Má gestão.

Em concomitância com as problemáticas sumas citadas, Chiavenato elenca que para desenvolver uma equipe coesa e altamente eficiente, o administrador empreendedor precisa ter conhecimento sobre:

Como formar a equipe: promova adequadamente o recrutamento e a seleção do pessoal, procurando sempre pessoas dinâmicas que possam agregar valor à empresa. Forme sua empresa com pessoas que vocề julgar serem melhores que você, para que elas tragam resultados ao seu negócio. Considere-as suas parceiras no negócio. Como preparar a equipe: proporcione o contínuo treinamento e desenvolvimento das pessoas. Faça com que, diariamente, cada pessoa agregue mais valor às suas habilidades, aos seus conhecimentos e ao seu trabalho. Ao investir na melhoria das pessoas, vocề estará apostando diretamente na melhoria do seu próprio negócio. Como remunerar a equipe: assegure salários e remunerações condizentes, além de benefícios materiais. Estabeleça objetivos desafiadores e oriente as pessoas em direção a eles, sem deixar de avaliar, reconhecer publicamente e recompensar o desempenho excelente. Cada conquista merece ser festejada, cada vitória precisa ser comemorada. Como desenvolver clima e cultura: crie uma atmosfera calorosa e agradável de trabalho e de espírito de equipe que possibilite a inovação, a melhoria contínua, a excelência, a participação e o comprometimento das pessoas. (CHIAVENATO, 2012, p. 54).

Por meio desse artigo busca-se despertar o intraempreendedorismo de colaboradores e motivá-los para que compreendam a importância de crescer profissionalmente, incluindo seus retornos financeiros. Além disso observou-se uma falha na cultura de valorização dos funcionários que buscam novos conhecimentos e novos métodos a serem implantados em seus trabalhos.

\section{COMPREENSÃO DA REALIDADE}

Chiavenato (2012, p. 7) descreve que "o espírito empreendedor envolve emoção, paixão, impulso, inovação, risco e intuição, mas deve também reservar um amplo espaço para a racionalidade." Partindo desses pressupostos, após alinhamentos em iniciais do plano de trabalho, optou-se por observar a realidade do grau de engajamento dos colaboradores de algumas grandes e pequenas empresas do cotidiano dos autores deste artigo.

Através dessas observações identificou-se que os colaboradores de uma empresa local com mais de 2 anos de vigência do contrato de trabalho possuem baixa motivação e não se mostram interessados em meios que possam complementar suas formações e melhorar seu rendimento dentro da organização, assumindo atitudes de uma pessoa estagnada, sem motivações para galgar novos postos de trabalhos possíveis pelo plano de carreira. Identificou-se também oportunidades na empresa observada a nível de lideranças operacionais e executivas.

Para consolidação das observações foram analisados questionário individuais de colaboradores preenchida por seus gestores, comprovando a queda de rendimento após completarem 2 anos em seus trabalhos, na maior parte dos casos.

Para Chiavenato (2012, p. 177) "as empresas estão envolvidas em um processo de transformação de recursos em produtos/serviços, como toda empresa é constituída de pessoas, ela é, na realidade, um sistema social." O autor ainda ressalta que toda organização consiste em uma combinação administrada de tecnologia e de pessoas. Os pontos destacados pelo autor evidenciam a necessidade do 
alinhamento e engajamento de todos os entes envolvidos na jornada pelo sucesso da organização, uma vez que os aspectos tecnológicos permitem o progresso e as pessoas realizam as atividades, porém a administração é que determina o ritmo e destino a serem trilhados.

Em suma, o empreendedor deve utilizar o que existe de mais importante em cada pessoa: o seu cérebro, a sua inteligência, as suas competências e a sua participação emocional. Saber gerenciar pessoas é saber extrair delas o que têm de melhor para fazer um trabalho excelente, ser uma extensão do empreendedor na melhoria contínua do trabalho e na excelência do produto/serviço e no ótimo atendimento ao cliente. (CHIAVENATO, 2012, p. 182)

Após as análises embasadas por autores de renome, as observações advindas da realidade vivenciada e identificações de problemas, pontuou-se os fatores imediatos e os condicionantes maiores associados ao problema em questão:

Possíveis fatores imediatos:

- A falta de liderança de muito gestores que agem como chefes, desmotivando seus subordinados;

- Falta de comprometimento dos funcionários com maior tempo de empresa, tendo seus interesses voltados apenas ao salário oferecido e não compromissados $100 \%$ com os produtos e os ideais da empresa;

- Falta de treinamento qualificado.

Possíveis condicionantes maiores:

- Aspectos tais como a falta de motivação dos funcionários, considerando que o Brasil é um muito assistencialista, onde a maioria da população não almeja grandes cargos;

- Cultura organizacional que não estimula a inovação e resolução de problemas;

- Estratégia de médio e longo prazo em risco, uma vez que os colaboradores não acreditam no plano de carreira e, assim, não estimulam a gestão do conhecimento.

Considerando os fatores imediatos e os condicionantes maiores, associados ao problema relaciona-se alguns aspectos essenciais ou pontoschave:

- Empreendedorismo corporativo;

- Administração empreendedora;

- Gestão estratégica de negócios.

\section{O EMPREENDEDORISMO CORPORATIVO NO BRASIL}

Uma expressão que vem sendo muito utilizada nas empresas é o empreendedorismo corporativo, ou intraempreendedorismo. Para Pinchot (1989, p. 232) que popularizou o termo na década de 80 , o empreendedor não se refere somente a pessoa que cria a empresa, mas também os colaborares responsáveis e proativos com relação a prática de contribuir para soluções inovadoras. No momento atual a expressão intraempreendedorismo foi ajustada para empreendedorismo coorporativo, para nomear as ações nas empresas que motivam e dão a liberdade para que seus colaborares, que agem como empreendedores, assumindo o risco de implantar novos processos inovadores e que são criativos para soluções alternativas de problemas.

Para Dornelas (2008, p. 33), “o empreendedor corporativo é fruto valores, crença e atitudes, partilhado com todos os colaboradores da empresa, fazendo o mesmo se sentirem importantes e parte da empresa, assim, ajudando a criar uma cultura que constrói a história empreendedora da empresa."

Farrel (1993, p. 184) ressalta que "é de suma importância para as empresas comprometidas com o processo de inovação desenvolver a cultura empreendedora, mostrando aos colaboradores." O autor ainda esclarece que "é necessário buscar conhecer perfeitamente os clientes e os produtos da empresa, para pode explorar melhor o valor econômico e agregar um maior valor percebido para a marca."

Segundo matéria vinculada no jornal Estadão (2013, documento on-line), a empresa Google é um exemplo de uma empresa mundialmente conhecida 
que aplica o empreendedorismo corporativo, onde os colaboradores podem usar parte do seu tempo para investir em projetos pessoais paralelos que resultam em novos produtos e soluções para os clientes.

Diante do exposto, verificou-se que se faz necessário por parte do dono da empresa, uma postura de gestor corporativo, de modo a despertar em seus colaboradores o sentimento de que estes também são sócios, exercendo a gestão participativa, mantendo vivo espírito empreendedor da empresa e valorizando a criatividade e participação dos cooperadores.

Compreende-se que o empreendedorismo corporativo é um excelente caminho para a inovação, e que um funcionário que é valorizado trabalha mais motivado e contribui positivamente com os resultados da empresa.

\section{ADMINISTRAÇÃO EMPREENDORA}

No início dos anos 80 as empresas japonesas impuseram uma reviravolta nas empresas americanas que até então dominavam o mercado. A obra de Ouchi (1985), ajudou diretamente a criar um modelo de administração empreendedora para as empresas americanas que ainda aplicavam a administração tradicional.

Este modelo se baseava em algumas características inovadoras e modernas, que se resumiam em 6 partes:

Unidades independentes de negócio: as UIN's são subdivisões da empresa por área de negócio, onde cada departamento da empresa se tornaria "pequenas empresas", com autonomia operativa e mercadológica, dando mais autonomia aos colaboradores e extraindo resultados uma análise segmentada facilitando o controle;

Equipes Empreendedoras: equipes lideradas por um empreendedor com finalidade de inovar e buscar novos negócios para empresa, além de, desenvolver as habilidades empreendedoras nos liderados;

"Intrapreneur": No português intraempreendedorismo, criado por PINCHOT III (1989), os colaboradores atuam como se fossem verdadeiros donos da empresa, buscando soluções inovadoras, ideais de novos produtos e conquistar objetivos;

Alianças e parcerias: objetivo é criar parcerias para esquivar-se da concorrência, compartilhando entre si, investindo em lançamento de novos produtos, pesquisa e desenvolvimento tecnológico;

Participação nos resultados: é a recompensa paga aos colaboradores pelo resultado em relação ao lucro da empresa, interesse é criar uma cultura de trabalho orientada no benefício de ambas as partes (empresa e colaborador);

Alternativas de Carreira: modelo de carreira em " $Y$ " onde o colaborador tem oportunidade de escolher entre carreira técnica ou empreendedora. (OUCHI, 1985, apud SANTOS et al. 2001, p. 22)

Desse modo, ampliou-se a visão sobre a administração empreendedora, mostrando que este modelo que busca desenvolver ações internas e externas que buscam nova oportunidades de negócio, alinha o colaborador para o mais próximo possível dos objetivos da empresa, dando autonomia e liberdade para suas tomadas de decisão.

Chiavenato (2012, p. 167) destaca que o administrador empreendedor "deve transformar uma mudança, que possa ser encarada como um risco pessoal, em algo que signifique realmente uma oportunidade pessoal de melhoria e de desenvolvimento." O autor propõe que a administração participativa exige três aspectos fundamentais: envolvimento mental e emocional das pessoas; motivação para contribuir; aceitação da responsabilidade.

Pelo exposto até então, pode-se afirmar quanto à viabilidade de dar autonomia ao colaborador, que a empresa deve estar preparada para correr riscos, mas se o cooperador estiver comprometido com o crescimento da empresa, existe uma grande chance de alavancagem. Para alcançar tal objetivo, é imprescindível que haja bons líderes, treinamento e políticas benéficas para garantir que o trabalhador esteja comprometido e motivado. 
6

\section{GESTÃO ESTRATÉGICA DE NEGÓCIO}

Dornelas (2008, p. 49) afirma que "para se criar um negócio de sucesso o empreendedor deve ter a capacidade identificar oportunidades, somado ao fato de assumir os riscos sabendo otimizá-los." Alguns aspectos são fundamentais para este papel, como ter iniciativa na formação do negócio e/ou ideia, criatividade na execução dos recursos e submissão aos riscos existentes em todo negócio.

Chiavenato (2007) relata que "o planejamento estratégico é um processo de formulação de estratégias organizacionais no qual se busca a inserção da organização e de sua missão no ambiente em que ele está atuando." O principal objetivo da gestão estratégica é otimizar riscos, detectar possíveis oportunidades e as ameaças, fatores positivos e negativos, buscar assim maior eficiência e ampliar os lucros dos processos e diminuir os prejuízos e desperdícios. A identificação desses fatores é um grande passo na caminhada de uma empresa sustentável.

Ainda na visão de Chiavenato (2012, p. 32), "as pessoas são peça fundamental nas empresas e organizações para que consigam lograr êxito em atingir seus objetivos e cumprir suas metas." Para isso, faz-se necessário ter colaboradores que estejam bem treinados e as estratégias do negócio devem ser claras, objetivas e de fácil interpretação a fim de que estejam comprometidos ao seu cumprimento.

Para que uma empresa seja sustentável é eminente que haja uma boa gestão e um planejamento de negócio, mas para que seja cumprido com excelência é preciso que a empresa forneça treinamentos para que todos os colaboradores estejam aptos a executar suas funções e tenham ciência com clareza das metas e objetivos a serem cumpridos.

Em síntese, a pesquisa da literatura se constituiu condição básica para a apresentação das hipóteses de solução dadas ao problema eleito para o presente estudo.

\section{HIPÓTESES DE SOLUÇÃO DO PROBLEMA}

A reflexão dos aspectos desenvolvidos pela pesquisa realizada com base na literatura, em especial o livro Empreendedorismo: transformando ideias em negócios (Dornellas, 2008), proporcionou um conhecimento mais abrangente do que foi observado na realidade, confirmando também os pontos chave esclarecidos no escopo deste artigo. Nesta etapa, apresentam-se diversas alternativas que contribuem para a solução do problema explorado:

- Desenvolver Plano de carreira e estabelecer na empresa;

- Criar um plano de participação de lucros por resultado aos colaboradores;

- Ofertar treinamentos/workshops motivacionais;

- Realizar feedbacks (modelo sanduiche) mensais;

- Incentivar o empreendedorismo corporativo.

Levantadas as hipóteses de solução buscou-se a verificar da viabilidade de aplicação a realidade delas e como foi realizado o processo.

\section{APLICAÇÃo À REALIDADE}

A partir da análise das hipóteses de solução, de uma reflexão acerca dos fatores imediatos e das condicionantes maiores, bem como do contexto no qual se encontra o problema em questão, foi possível eleger algumas contribuições para a solução do problema apresentado, com o objetivo de intervir na realidade da empresa, propondo ideias inovadoras que agregarão valor.

A aplicação à realidade para enfrentamento dos problemas levantados não foi realizada em virtude da pandemia da COVID-19, sendo aqui apresentadas as propostas possíveis de realização em um momento mais propício.

Diante dos problemas levantados, sugere-se as ações sendo realizadas pela seguinte proposta:

- Inicialmente a empresa terá que desenvolver um plano de carreira e este ser apresentado nos testes/entrevistas e aos seus colaboradores efetivados, reforçando as oportunidades que terão caso se destaquem; 
- Seguindo o fluxo da hipótese, após desenvolvido o plano de carreira e socializados com seus colaboradores, a empresa deverá fornecer treinamentos e/ou workshops motivacionais, a fim de fomentar o impulso aos colaboradores e gestores estagnados ou desmotivados;

- Posteriormente, nesta linha de raciocínio, é de extrema importância a realização mensal de feedbacks no modelo sanduiche, no intuito de relatar pontos de melhoria e reconhecimento dos resultados positivos apresentados pelos colaboradores;

- Além disso, o incentivo ao empreendedorismo corporativo é a etapa final para a hipótese de solução, visto que, a ideia principal é engajar os gestores e colaboradores a terem ideias criativas e inovadoras para a resolução dos problemas em questão, os mantendo ligados a empresa e como parte do processo gerando muitos benefícios para ambos.

Colocar tudo em prática torna-se engrandecedor para a organização e para os colaboradores que estão nela e seguir este pequeno fluxo que de início se parece simples, faz com que a empresa consiga usufruir ainda mais do potencial de todos seus colaboradores.

\section{9}

\section{CONSIDERAÇÕES FINAIS}

Com a constante evolução do mercado, aumento da competitividade e de empresas que oferecem serviços similares, torna-se cada vez mais necessário a elaboração de estratégias de gestão para que a empresa se destaque e aperfeiçoe o relacionamento com o cliente.

Ocorre que alguns fatores se mostram como óbices ao objetivo de manter e aperfeiçoar um padrão de excelência na prestação de um serviço ou fornecimento de um produto. Existe uma tendência do colaborador em diminuir seu rendimento e a produtividade com o passar do tempo. Isso se dá por diversos fatores, como a sensação de estabilidade e a falta de motivação.
Além disso, líderes que não incentivam seus colaboradores e a deficiências organizacionais da interferem negativamente nos resultados do empreendimento, uma vez que refletem diretamente no produto/serviço e na percepção do cliente.

Um dos melhores caminhos a serem traçados para driblar os obstáculos supracitados, e que tem se mostrado eficiente na prática, é o empreendedorismo corporativo, quando os indivíduos em conjunto buscam se colocar em uma nova organização ou a inovação dentro de uma já existente.

Esse modelo se propõe a encontrar novas oportunidades de negócios, novas ideias e despertar no colaborador o desejo de ascender na empresa e fazer com que se comporte como se dela fosse dono. Sendo assim, conclui-se que o cooperador exerce papel fundamental, ao passo que, ao inserilo em estrutura organizacional eficiente, que tenha como ideais sua valorização e abra espaço para novas ideias, será aberto um leque de oportunidades e possibilidades de alavancagem do empreendimento.

Desse modo, mostra-se como solução para os problemas apresentados o desenvolvimento de um plano de carreira atraente, a criação de um plano de participação final nos lucros pelos colaboradores, oferecer um treinamento eficiente e incentivar o empreendedorismo corporativo.

Se o gestor conquistar a participação dos colaboradores atuantes, não apenas como cumpridores de ordem e tarefas, mas como verdadeiros empreendedores que contribuem com novas ideias, a chance de sucesso da empresa, bem como de seu crescimento, se tornam muito maiores.

\section{REFERÊNCIAS}

CHIAVENATO, Idalberto. Empreendedorismo: Dando Asas ao Espírito Empreendedor. 4. Ed. Barueri, SP: Manole, 2012.

CHIAVENATO, Idalberto. Administração: teoria, processo e prática. Rio de Janeiro. Elsevier, 2007.

CURY, Augusto Jorge. Dez leis para ser feliz: ferramentas para se apaixonar pela vida. Rio de Janeiro: Sextante, 2003. 
DORNELAS, José. Empreendedorismo corporativo: como ser empreendedor, inovar e se diferenciar na sua empresa. Rio de Janeiro: Elsevier, 2003.

DORNELAS, José. Empreendedorismo fazendo acontecer - Livro do Professor - Volume 2. São Paulo: Empreende, 2020.

DORNELAS, José Carlos. Empreendedorismo: transformando ideias em negócios. 3 a edição. Rio de Janeiro: Elsevier, 2008.

FARREL, Larry C. Entrepreneurship: fundamentos das organizações empreendedoras. São Paulo: Atlas, 1993.

FERNANDES, D. Google dá $20 \%$ do tempo para funcionário. E você? Estadão, 2013. Disponível em: https://pme.estadao.com.br/blogs/blog-doempreendedor/o-google-da-20-do-tempo-para-ofuncionario-e-voce/. Acesso em: 03 de jun. 2020.

PINCHOT, Gifford III. Intraempreendedor: Porque você não precisa deixar a corporação para se tornar um empresário. University of Illinois at UrbanaChampaign's Academy for Entrepreneurial Leadership Historical Research Reference in Entrepreneurship, 1989.

SANTOS, A.R.; PACHECO, F.F.; PEREIRA, H. J.; BASTOS Jr, P.A. Gestão do conhecimento como modelo empresarial. Gestão do conhecimento: uma experiência para o sucesso empresarial. Rio de Janeiro: Campus. 2001. 